\section{LIGHT UP YOUR WORKING DAY}

The CEREC Bluecam CAD/CAM from Sirona Dental Systems illuminates the treatment area perfectly allowing you to capture near inaccessible areas of the mouth with the utmost of precision.

With automatic image capture the CEREC Bluecam automatically detects the right moment to trigger the exposure. Shake-free images are guaranteed with the built-in shake detection system; this combined with the short capture time ensures that images are acquired only when the camera is still. The outstanding depth of field generates high precision images, particularly useful around the margins where a perfect fit of the final prosthesis is essential. You can even acquire difficult inlay preparations in 3D with a single exposure.

The compact CEREC Bluecam allows easy access to the posterior region of the mouth making the experience more comfortable for your patient; with a quadrant being captured in a matter of seconds there is no comparison in terms of comfort and time saving for you and your patient when compared to traditional impression taking. Another time saving benefit that can easily be achieved with CEREC Bluecam is long term temporary crowns and bridges. These can be designed, produced and placed chairside in a single treatment.

Isn't it time your practice was lit up with CEREC Bluecam from Sirona Dental Systems?

For further information call 0845071 5040, email mark. buckland@sironadental.co.uk or visit www.sirona.com.

\section{THE LATEST INTRAORAL SENSORS}

Investing in Schick's Digital Imaging System not only gives your dental practice an advantage in terms of convenience in imaging: it makes operations more efficient and more profitable too.

Schick's system offers a completely integrated range of the latest intraoral sensors, including the CDR Elite, developed in association with a panel of leading dental radiologists and authenticated by many leading dental practitioners. Schick also offers a WiFi option for the ultimate in versatility.

With no film costs, Schick sensors can start contributing to the bottom line of your practice as soon as they are paid for, while offering patients the very best in care.

Clark Dental is a family run company with over 36 years' experience - dedicated to dentistry.

For more information contact Clark Dental on 01268 733146, email enquiries@clarkdental.co.uk or visit www.clarkdental.co.uk.

\section{DUAL-SHIELD DESIGN AND BACKSCATTER SCREEN}

Rextar X is the new safe handheld intraoral X-ray unit from Digital Dental.

The new Rextar X has a sealed dual-shield design and a backscatter screen to protect the operator. The new $70 \mathrm{kV}$ generator ensures a shorter exposure time, higher image quality and a very low dose for the patient. This means the operator dose from the new Rextar X is similar or less than using a wall-mounted X-ray unit. You don't have to leave the room so you can take X-rays faster and it helps reduce retakes. Your patients feel more at ease, too, because you stay chairside and their exposure is kept to a minimum.

The Rextar $\mathrm{X}$ is similar in price to a high quality wall-mounted unit. It is lightweight and portable, so you can share it between surgeries or have an instant back up for your existing X-ray units. Rextar X is programmable for easy one-touch use with film, sensors or phosphor plates.

Manufactured to the highest standards and CE certified, Rex$\operatorname{tar} \mathrm{X}$ is the future of intraoral $\mathrm{X}$-ray units.

Visit www.digitaldental.co.uk or call 08007565642.

\section{THE MOST FAVOURABLE WORKING SPACE}

The Skema 8 dental unit from Castellini has been tailored for the convenience of both the dentist and the patient. With remarkable ease of use and

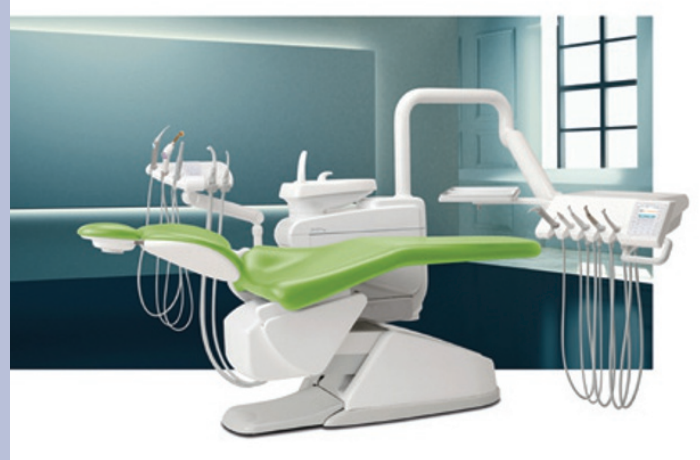

a streamlined design, the incomparable Skema 8 is at the summit of patient comfort and dental precision.

Ensuring uncomplicated use for all classic two and four handed procedures, the Skema 8 employs an innovative sliding action which enables a synchronised movement between the seat and backrest of the patient's chair. As the chair rises, the backrest reclines providing the most favourable working space for the clinician.

The needs of the dentist are fulfilled with the Skema 8, allowing optimum space to ensure that the dentist's abilities are maximised. With a highly advanced control panel made from tempered glass and powered by a cutting edge microprocessor, the Skema 8 takes a giant leap forward in comfort and convenience.

The Skema 8 allows dentists to operate under the most advantageous conditions, and proves that it is the pedigree of sophisticated dental units.

Telephone 08000933975 for details of your local Castellini dealer.

Castellini has service centres throughout the UK. 